\title{
Mulher e mercado: participação e conhecimentos femininos na inserção de novas espécies de pescado no mercado e na dieta alimentar dos pescadores da RESEX Mãe Grande em Curuçá (PA) \\ Women and market: female participation and knowledge in the insertion of new species of fish in the market and in the diet of fishermen RESEX Mãe Grande of Curuçá (PA)
}

\author{
Marllen Karine da Silva Palheta', Voyner Ravena Cañetel, Denise Machado Cardosol \\ Universidade Federal do Pará. Belém, Pará, Brasil
}

\begin{abstract}
Resumo: $O$ artigo descreve como o conhecimento tradicional da mulher marisqueira e pescadora de rio e mar, da localidade de Caratateua, RESEX Marinha Mãe Grande de Curuçá (PA), contribui na inserção e comercialização de novas espécies de pescado. O trabalho utiliza metodologia quali-quantitativa e produz dados que apontam para um quadro de escassez dos pescados mais apreciados no mercado local. Apresenta o conhecimento tradicional feminino sobre as espécies-chave que compõem a dieta dos pescadores, sendo esse uma forma de inserção das mulheres no mercado. A coleta dos dados ocorreu no período de março a agosto de 2012. As técnicas metodológicas utilizadas priorizaram um fazer etnográfico, privilegiando o uso de entrevistas semiestruturadas, realizadas com pescadoras/marisqueiras da comunidade, sendo aplicados, ainda, dez questionários às mesmas e nove questionários no mercado do município de Curuçá, junto aos vendedores de pescado. Nas entrevistas, foi possível observar as mudanças ocorridas ao longo dos anos, evidenciando a escassez das espécies tradicionais, tanto na mesa do pescador quanto no mercado consumidor. Os resultados apontam, especialmente, para o papel da mulher na inserção de novas espécies em ambos os espaços, privado e do mercado, já que o conhecimento feminino evidencia uma maior percepção acerca dos recursos naturais disponíveis para consumo.
\end{abstract}

Palavras-chave: Conhecimento tradicional. Trabalho feminino. Dieta. Mercado.

Abstract: The article describes how the traditional knowledge of fisherwomen of river and sea in the town of Caratateua, RESEX Marinha Mãe Grande de Curuçá (PA), contributes to the integration of new species of fish in the marketing. The work uses a qualitative and quantitative methodology and produces data that point to a shortage of fish picture of most popular in the local market. It presents the female traditional knowledge on key species that make up the diet of fishermen, and this is a way to insert woman in the market of fishery. Data collection occurred from March to August 2012. The methodological techniques prioritized an ethnographic do, favoring the use of semi-structured interviews with fisherwomen / community seafood restaurants, being applied also 10 questionnaires to them and 9 questionnaires in market Curuçá municipality next to the fish vendors. In the interviews we observed the changes over the years, reflecting the scarcity of traditional species, both in the fisherman diet as the consumer market. The results point especially to the role of women in the insertion of new species in both spaces, private and market, since women's knowledge means a greater perception of natural resources available for consumption.

Keywords: Traditional knowledge. Women's work. Diet. Market.

PALHETA, Marllen Karine da Silva; CAÑETE, Voyner Ravena; CARDOSO, Denise Machado. Mulher e mercado: participação e conhecimentos femininos na inserção de novas espécies de pescado no mercado e na dieta alimentar dos pescadores da RESEX Mãe Grande em Curuçá (PA). Boletim do Museu Paraense Emílio Goeldi. Ciências Humanas, v. 11, n. 3, p. 601-619, set.-dez. 2016. DOI: http://dx.doi.org/10.1590/1981.81222016000300004.

Autora para correspondência: Marllen Karine da Silva Palheta. Universidade Federal do Pará. Avenida Augusto Corrêa s/n. Belém, PA, Brasil. CEP 66075-110 (marllenkarine@yahoo.com.br).

Recebido em 30/09/2013

Aprovado em 15/08/2016

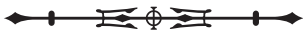




\section{INTRODUÇÃO}

A pesca na Amazônia é uma das principais atividades econômicas da região, tradicionalmente passada entre gerações e constituindo-se em fonte de alimento e de renda, principalmente para a população ribeirinha residente ao longo dos rios amazônicos. Desde o período pré-colonial, a pesca foi exercida na Amazônia de forma intensa, tendo como principais alvos de captura o peixe-boi (Trichechus inunguis), a tartaruga (Podocnemis expansa) e o pirarucu (Arapaima gigas), desencadeando, no transcorrer do tempo, uma redução nas populações desses animais (Torres, 2004). Atualmente, a pesca dessas espécies foi regulamentada, sendo proibida a pesca do peixe-boi e da tartaruga (Santos, G.; Santos, A., 2005).

O estado do Pará se destaca no setor pesqueiro na região Amazônica por possuir um extenso litoral marinho com 562 km, correspondendo a 7\% da costa brasileira. Devido a tais características, a atividade pesqueira é considerada uma das mais importantes no estado, principalmente pela relevância econômica de seus recursos pesqueiros (Santos, L., 2005). O Pará encontra-se dentro do estuário amazônico ${ }^{1}$ e se destaca pelo ambiente adequado ao ciclo reprodutivo de variadas espécies, dispondo de excelentes condições para a atividade pesqueira, que possui grande importância econômica para a região (Oliveira; Frédou; Lucena, 2007).

No entanto, ainda que dotada de recursos variados, a pesca no estado vem sofrendo com a sobre-exploracão dos estoques pesqueiros devido ao aumento desordenado do esforço de captura ${ }^{2}$, principalmente ocasionado pela pesca industrial ${ }^{3}$, seguida da pesca artesanal ${ }^{4}$ ou de pequena escala. As espécies de maior valor comercial dentro desse quadro são: a gurijuba (Arius parkeri, Trail, 1832), serra (Scomberomorus brasiliensis, Russo; ZavalaCamin, 1978), pescada amarela (Cynoscion acoupa, Lacepède, 1801), piramutaba (Brachyplatystoma vaillantii, Valenciennes, 1840), pargo (Lutjanus purpureus, Poey, 1876) e camarão-rosa (Farfantepenaeus subtilis, PérezFarfante, 1967).

De acordo com Sousa et al. (2008), Isaac-Nahum (2006), Bentes (2004) e McGrath et al. (1996), esse quadro de sobre-exploração se deve ao avanço tecnológico da pesca na Amazônia 5 nas últimas décadas e à grande expansão demográfica dos centros urbanos. Essas mudanças proporcionaram o crescimento na demanda de pescado, colaborando para uma maior exploração dos estoques pesqueiros.

\section{A RESEX Extrativista Mãe Grande de Curuçá} (doravante nominada Resex MGC) é uma unidade

O estuário do Amazonas encontra-se entre os estados do Pará e Amapá, banhado pelos rios Amazonas e Tocantins, que desaguam no Oceano Atlântico. É formado por um ambiente aquático complexo, de alta produtividade biológica, suportando uma biomassa substancial de espécies de pescado, exploradas por frotas artesanais e industriais em ambos os estados. O estuário amazônico é considerado uma das regiões mais produtivas nacionalmente, tido como um grande polo industrial de exploração de recursos pesqueiros (Oliveira; Frédou; Lucena, 2007).

2 Diferentes literaturas definem esforço de pesca, também conhecido como esforço de captura, que pode ser entendido como a ampliação dos incrementos tecnológicos, tempo de atividades envolvidas e percurso realizado para a pesca, buscando aumentar ou manter a produção dessa atividade (Isaac-Nahum; Barthem, 1995).

3 A pesca industrial é definida como um tipo de atividade voltada para o mercado, nacional e internacional, que utiliza barcos de mais de 20 toneladas e tecnologia sofisticada (Pinheiro; Frédou, 2004).

4 A pesca artesanal na região da Amazônia brasileira é uma importante fonte de renda e fornecimento de alimentos à população local. A pesca é caracterizada pela diversidade de artes, algumas bastante primitivas e de origem tradicionais, tendo como alvo de captura uma enorme diversidade de espécies, destinados para o consumo e comercialização em mercados regionais e nacionais (Isaac-Nahum; Rufino, 2000; Bentes, 2004).

5 Segundo Isaac-Nahum (2006, p. 33), "o litoral amazônico, que inclui a linha de costa dos estados do Pará e do Amapá, possui uma vocação natural para a exploração de recursos pesqueiros. As zonas costeiras paraense e maranhense possuem uma grande diversidade íctica e são reconhecidas pela riqueza de recursos pesqueiros demersais, alguns deles muito explorados, mas a maior parte das vezes ainda com potencial desconhecido. A pesca é uma das atividades mais tradicionais e garante renda e subsistência para uma boa parte da população, além de render importantes divisas para o país".

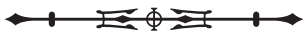


de conservação ambiental marinha, com uma área de aproximadamente $36.678,24$ hectares, considerada uma das mais importantes unidades de conservação situadas na costa amazônica ${ }^{6}$, integrando 52 comunidades de pescadores e agricultores ${ }^{7}$. Segundo Figueiredo (2007), a principal atividade econômica do município de Curuçá está ligada à atividade pesqueira industrial e artesanal, com projeto concreto de construção de um porto na região, cuja a finalidade é o escoamento de produtos nacionais.

Diante do quadro de exploração de recurso pesqueiro já mencionado, a participação feminina na pesca aumentou gradativamente com o passar dos anos, pois novas atividades foram introduzidas para complementar o orçamento familiar. Segundo Maneschy (2000), a condição feminina na pesca pode ser assim classificada: marisqueiras, as tecedeiras de redes de pesca, pescadoras de praias e rios, beneficiadoras de pescado, as que fazem farinha de pescado, as ex-pescadoras, as esposas e filhas de pescadores e as presidentes ou membros de diretorias de colônias ou de outras associações de pescadores.

A mulher desempenha diversas funções de extrema importância no cotidiano das comunidades pesqueiras artesanais. A partir dos recursos do ecossistema terrestre e aquático, geram renda e complementam o sustento familiar, valorizando, assim, os recursos naturais locais. Participam, ainda, de organizações sociais, a fim de buscar seus direitos e reconhecimento social (Maneschy, 2000). Sendo assim, são as mulheres que, convivendo diariamente com as dificuldades cotidianas, diferindo dos homens vinculados às longas viagens e atividades no mar, findam responsáveis pela casa e pela responsabilidade da alimentação das famílias dos pescadores. As mulheres são, portanto, as responsáveis pela introdução de novas espécies de peixes sem valor comercial à dieta dessas famílias, diante da escassez das espécies valorizadas comercialmente.

Incluir a perspectiva das relações sociais de gênero contribui de maneira significativa no estudo sobre a importância da mulher e seus conhecimentos naquilo que se refere à pesca, na comercialização de espécies daí advindas e no incremento do mercado local. Diante disso, as leituras acerca da inserção feminina em ambiente social e atividade considerada majoritariamente masculina, como é o caso da pesca, devem ser problematizadas.

Assim, é importante questionar em que medida o conhecimento tradicional da mulher contribui para a inserção e comercialização de novas espécies de pescado no mercado local e em que medida esse conhecimento garante novas espécies na mesa das famílias de pescadores. Constitui-se como objetivo principal deste trabalho, portanto, descrever como o conhecimento tradicional da mulher marisqueira e pescadora de rio e mar, da localidade de Caratateua, na RESEX Marinha Mãe Grande de Curuçá, contribui na inserção e comercialização de novas espécies de pescado no mercado local. O trabalho apresenta dados que apontam para um quadro de escassez das espécies há muito apreciadas, assim como apresenta o conhecimento tradicional feminino sobre as espécieschave que compõem a dieta dos pescadores como uma das formas de inserção de novas espécies no mercado local. $\bigcirc$ trabalho descreve, ainda, as espécies que foram inseridas no sistema a partir do conhecimento feminino.

\section{METODOLOGIA}

A construção do presente artigo foi realizada por uma abordagem quantitativa e qualitativa, utilizando inicialmente

\footnotetext{
6 Nos últimos anos, o município de Curuçá vem sendo objeto de estudo, em especial nos programas de pós-graduação da UFPA, originando trabalhos que permitem compreender diversos aspectos acerca do município, como população e meio ambiente. Para saber mais, consultar Almeida (2009), Palheta (2005), Figueiredo (2007), Queiroz (2011), Batista (2010), Martins (2010), Chaves (2010), Hercos (2006), Silva (2011) e Morais (2011).

7 Dado de campo, obtido em entrevista com o presidente da colônia de pescadores em janeiro de 2012.
}

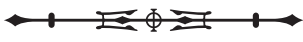


as técnicas de survey ${ }^{8}$ para a coleta de dados, acrescida de uma pesquisa bibliográfica e, posteriormente, acompanhada de estadas em campo para observação direta dos contextos de pesca orientados e organizados pela presença da mulher. A primeira viagem a campo ao município de Curuçá buscou levantar informações que levaram à escolha da comunidade de Caratateua para a realização do estudo.

Pertencente ao município de Curuçá, Caratateua integra o domínio territorial da RESEXMGC, localizada no nordeste do Estado do Pará, a 160 km da capital, Belém; a 30 km de Curuçá; e a 4,5 km da PA-318. A comunidade apresenta como principal atividade econômica a pesca. Nessa localidade, a participação feminina na atividade pesqueira é bem acentuada, tanto na pesca de mar como na atividade de mariscagem, o que a destacou como opção na escolha para estudo. Agregada ao survey e à observação direta, já mencionados, a coleta de dados fez uso da observação participante ${ }^{9}$, além do uso de entrevistas semiestruturadas.

Para a entrevista na comunidade com as marisqueiras, adotou-se a idade como critério de escolha, fazendo uso da faixa etária entre 15 e 65 anos, com o intervalo de 10 anos entre cada faixa etária. A escolha do critério mencionado repousou no fato da diferença de idade influenciar nos conhecimentos tradicionais relacionados à pesca, dado que, como aponta Woortmann (1991), as mulheres de mais idade são as mais respeitadas e valorizadas na comunidade, por terem um conhecimento mais apurado dos recursos naturais; já as mais novas são vistas como menos importantes, por não terem esse domínio ou, até mesmo, não evidenciarem interesse em tê-lo, voltando-se quase que exclusivamente para atividades do lar. Quanto mais idade, maior a experiência acerca da atividade. Nesse sentido, essa escolha metodológica possibilitou observar como esse conhecimento é abordado entre diferentes gerações.

No total foram realizadas 10 entrevistas, sendo entrevistadas duas mulheres para cada uma das faixas etárias estabelecidas. Para finalizar a pesquisa de campo, foram realizadas entrevistas com os vendedores de pescado do mercado municipal de Curuçá, a fim de verificar quais espécies adentraram o mercado nos últimos anos, tendo sido entrevistados nove vendedores ao total. A pesquisa descrita ocorreu no período de março a agosto de 2012, sendo que a permanência em campo foi em média de 10 dias para cada viagem à comunidade, totalizando quatro viagens a campo.

\section{CONHECIMENTO TRADICIONAL FEMININO}

As sociedades tradicionais são grupos humanos diferenciados do ponto de vista cultural, reproduzindo seu modo de vida, de forma mais ou menos isolada, tendo embasamento na cooperação social e relação com a natureza (Diegues; Arruda, 2001). Segundo Arruda (2000) essa relação pode ser encontrada junto aos povos indígenas ou em populações tradicionais, por terem desenvolvido modos específicos de existência e adaptações ao meio em que vivem.

De acordo com Diegues e Arruda (2001), as populações tradicionais são classificadas em várias modalidades, tais como: comunidades caiçaras, sitiantes e roceiros, quilombolas, ribeirinhos, pescadores artesanais, grupos extrativistas, indígenas, dentre outras tantas e diversas comunidades com formas específicas de se relacionar e usar os recursos naturais.

8 Definição de survey: "A pesquisa survey pode ser descrita como a obtenção de dados ou informações sobre características, ações ou opiniões de determinado grupo de pessoas, indicado como representante de uma população alvo, por meio de um instrumento de pesquisa, normalmente um questionário. É uma pesquisa apropriada quando se deseja responder a tais questões: o que? Por que? Como? E quanto? Ou seja, quando se pretende saber 'o que está acontecendo' ou 'como e por que isso está acontecendo" (Freitas et al., 2000).

9 A observação participante figura como um método de pesquisa desenvolvido nos primeiros anos do século XX, resultante do trabalho de campo de Malinowski, entre os anos de 1914 e 1918. Segundo Malinowski (1976), quando se vive na aldeia, sem qualquer responsabilidade a não ser a de observar a vida nativa, o pesquisador observa os costumes, festas, atividades cotidianas etc., muitas vezes absorve suas crenças, passando a viver por um determinado tempo a vida do nativo. Portanto, a observação participante complementa a entrevista semiestruturada. Vale salientar a necessidade de reunir critérios, tais como responder a objetivos prévios, ser planejada de modo sistemático, sujeita à validação e verificação, precisão e controle.

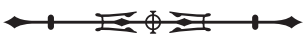


A partir da lei de $n^{\circ} 9.985$, de 18 de julho de 2000 (Brasil, 2000), foi instituído o Sistema Nacional de Unidades de Conservação (SNUC) ${ }^{10}$; nela, defini-se como população tradicional aqueles povos cuja subsistência se fundamenta no extrativismo, como atividade complementar à agricultura de subsistência, e na criação de animais de pequeno porte. Essas populações se baseiam no uso sustentável dos recursos naturais, realizado ao longo de gerações, apresentando uma função de extrema importância na proteção da natureza e da diversidade biológica.

Segundo Cunha (1999), o conhecimento tradicional produz um saber valioso que o mercado está começando a conhecer, possuindo um valor próprio e independente de parâmetros de verdade. Esse saber local não deve ser desprezado, mas sim valorizado na construção do uso sustentável dos recursos naturais. Considerando as características desse conhecimento e, do ponto de vista da manutenção dos recursos naturais, o papel da mulher nas comunidades pesqueiras é de grande importância para o meio ambiente, visto que elas possuem uma relação de proximidade com a natureza através dos conhecimentos tradicionais adquiridos nas relações geracionais. Esses conhecimentos possuem extrema importância para a conservação das espécies, em especial as que estão ameaçadas pela sobre-exploração dos recursos pesqueiros. Como visto, a mulher exerce um papel dinâmico no âmbito familiar, exercendo várias atividades, como os cuidados da família, a criação de animais, a roça, o transporte de água, a lenha, finalmente integrando esse saber tradicional (Cardoso, 2007; Almeida, 2002).

Mesmo constatando essa participação de mulheres na pesca, há uma invisibilidade de suas atividades devido ao modelo patriarcal de relações sociais. De acordo com os estudos sobre as relações sociais de gênero, esta situação é recorrente não apenas no que se refere ao trabalho, mas em outras atividades na qual há indicações de que caberiam aos homens exercê-las. Motta-Maués (1993), em estudo sobre comunidades pesqueiras no nordeste do Pará, já indicou que há interditos às mulheres naquilo que se refere ao exercício de poder político, religioso e no trabalho. Aos homens caberiam as atividades de liderança política, da pajelança e da pesca, e mesmo quando mulheres a exerciam havia discriminação e até mesmo invisibilidade de suas ações.

Além da pesca, o mundo do trabalho como um todo é marcado pelas diferenciações conforme o gênero. Alencar (1993) indica em seus estudos o quão significativo é este trabalho silenciado das mulheres e é exemplar o estudo de Simonian (2001), no qual aponta para o silenciamento das ações de mulheres em várias comunidades tradicionais e indígenas na Amazônia. Coelho (2013) amplia este escopo de estudos para além da pesca ao incluir o espaço das águas em sua investigação sobre o trabalho de mulheres na marinha mercante. Estes e outros estudos revelam atividades consideradas eminentemente masculinas sendo exercidas por mulheres, mas que são tratadas socialmente como inferiores devido às questões de gênero.

Os estudos de gênero iniciados em meados do século XX explicam que o processo de socialização se dá segundo o sexo biológico, de maneira dualista e hierárquica, de tal modo que cabe ao sexo feminino os espaços e atividades de menor valor social. Os estudos de Beauvoir (1980), Mead (1971) e Pateman (1996) são exemplares no que se refere à indicação de atividades e de comportamentos conforme o grupo social e cultural no qual os seres humanos são educados e, portanto, socializados. Desse modo, as relações afetivas, políticas e de trabalho são assentadas em lógicas

\footnotetext{
10 A lei de n 9.985, de 18 de julho de 2000 (Brasil, 2000) institui o Sistema Nacional de Unidades de Conservação da Natureza (SNUC), no qual estabelece critérios e normas para a criação, implantação e gestão das unidades de conservação. O SNU C divide em duas categorias as unidades de conservação: a de proteção integral, formada por Estação Ecológica, Reserva Biológica, Parque Nacional, Monumento Natural e Refúgio de Vida Silvestre, e a de uso sustentável, subdividida em Área de Proteção Ambiental, Área de Relevante Interesse Ecológico, Floresta Nacional, Reserva Extrativista, Reserva de Fauna, Reserva de Desenvolvimento Sustentável, Reserva Particular do Patrimônio Natural. O SNUC é uma das alternativas criadas pelo Governo Federal para criar áreas protegidas, a fim de resguardar a existência de meio ambiente ecologicamente equilibrado.
}

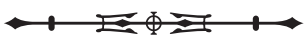


nas quais o espaço feminino é eminentemente o espaço doméstico. Contudo, à revelia destas regras baseadas no gênero, as mulheres ocuparam espaços que socialmente não lhes caberia, como é o caso da pesca.

$\bigcirc$ trabalho feminino na atividade pesqueira, nas últimas décadas vem crescendo e aparece de forma incisiva nas discussões em regiões com a economia voltada aos recursos pesqueiros. Segundo Maneschy (2000), a produção feminina nas comunidades pesqueiras é tão importante quanto a dos homens, embora não haja o devido reconhecimento como tal. A inserção da mulher na atividade pesqueira decorre de vários fatores, dentre estes o aumento da pobreza e da exclusão social das populações litorâneas, fazendo com que o trabalho feminino passe a ter suma importância na sobrevivência das famílias que vivem exclusivamente da pesca (Figueiredo; Santana, 2009). As mulheres, finalmente, atuam de forma a contribuir no orçamento doméstico, para tentar suprir as necessidades básicas de suas famílias (Maneschy, 1995).

É possível dizer, então, que a mulher findou por transitar entre o espaço doméstico e de mercado do setor pesqueiro. Esse movimento conferiu à mulher um domínio sobre dois mundos que se traduziu na possibilidade de, ao dominar conhecimentos sobre recursos pesqueiros, ampliar a inserção dos mesmos em um mercado com maior demanda. Assim, ao mesmo tempo em que a demanda por recursos pesqueiros se amplia no mercado, os estoques das espécies mais apreciadas diminuem. Coube à mulher oferecer, através de seu conhecimento, novas espécies para o mercado de consumo.

\section{MERCADO DO SETOR PESQUEIRO}

A pesca comercial foi uma das primeiras atividades econômicas da Amazônia colonial. Como mencionado, os recursos mais explorados eram a tartaruga-da-Amazônia, o peixe-boi e o pirarucu. $\bigcirc$ aumento da demanda por essas espécies levou a uma superexploração, baixando, assim, a disponibilidade desses recursos, se intensificando nos períodos de decadência de outros produtos regionais como a borracha e a juta (Isaac-Nahum et al., 2004).

Do pescado desembarcado em Belém, Santarém e Manaus, considerados os principais portos de desembarque na Amazônia, grande volume é destinado às indústrias, onde as empresas atuam tanto no mercado nacional, como internacional. No mercado nacional, as principais espécies comercializadas são a piramutaba (Brachyplatystoma vaillantii, Valenciennes, 1840), dourada (Brachyplatystoma flavicans, Castelnau, 1855), bagre (Bagre sp.) e camarão (Macrobrachium sp.). No mercado internacional, a preferência estende-se à venda de lagosta (Panulirus argus, Latreille, 1804) e camarão (Macrobrachium sp.) (Lopes et al., 2010).

$\bigcirc$ desenvolvimento da pesca comercial se deu desde o século XVIII no Baixo Amazonas, motivando a necessidade de medidas normativas de controle, a fim de reduzir ou evitar a captura irresponsável. Essas medidas podem ter colaborado para diminuir o impacto da pesca desde então; no entanto, não foram satisfatórias para ensejar o uso sustentável dos recursos e evitar a degradação de locais de várzea na região, bem como evitar a redução da disponibilidade dos recursos e o incremento dos conflitos dos usuários (Isaac-Nahum et al., 2004).

Aexpansão dapesca comercialnaAmazôniateve iníciona década de 1950, devido ao desenvolvimento na tecnologia de pesca, transporte e armazenamento dos produtos pesqueiros capturados. A introdução das fibras monofilamentosas foi a principal inovação tecnológica de captura e, consequentemente, o crescente uso de malhadeiras ${ }^{11}$.

\footnotetext{
11 Malhadeira - arte de pesca conhecida também como rede de espera retangular, confeccionada em náilon monofilamento; o entralhe superior (parte da rede que fica mais próxima da superfície) contendo uma série de boias e, no entralhe inferior (parte da rede mais próxima do fundo), pequenas peças de chumbo são alocadas para facilitar o afundamento. Possui diversos tamanhos de malha (de $5 \mathrm{~cm}$ a $19 \mathrm{~cm}$, entre nós opostos), dependendo da espécie alvo, com comprimento médio que varia de 70 m por panagem, com altura entre 1 m e 6 m (Relátorio Norte Energia, 2013). Disponível em: http://icenciamento.ibama.gov.br/Hidreletricas/Belo\%20Monte/Relatorios\%20Semestrais/4\%C2\%BARC\%20 FINAL\%2030.08.2013\%20-\%20PDF/CAP\%202/13/13.3/13.3.5/ANEXOS/Anexo\%2013.3.5\%20-\%202.pdf. Acesso em: 09 set. 2013
}

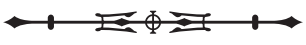


Outras inovações ocorreram durante esse período, como na área de transporte e tecnologia de armazenamento, modificando-se a frota pesqueira de vela para diesel, o que possibilitou aos barcos pesqueiros viagens cada vez mais longas em um curto período de tempo. Tais mudanças tecnológicas foram acompanhadas pelo elevado aumento populacional regional e pela exportação de peixes da Amazônia para os mercados nacionais e internacionais. Esse aumento ocorreu devido ao crescimento explosivo das cidades amazônicas nos anos de 1970 e 1980 (McGrath et al., 1991).

A indústria pesqueira da região Amazônica é responsável por absorver grande parte do volume de pescado local. Em Belém, para cada quilo de pescado desembarcado no mercado regional, aproximadamente três quilos são direcionados aos frigoríicos. Em Santarém, essa relação gira em torno de 50\%, ou seja, metade do pescado desembarcado no local é destinada aos frigoríficos. Em Manaus, apesar de ser um grande centro comercial de pescado, essa relação é um pouco diferente, de toda forma esses números revelam a grande participação da pesca no abastecimento industrial (Almeida et al., 2004).

O consumo de pescado no Brasil encontra-se diretamente ligado ao poder aquisitivo da população, à quantidade e qualidade ofertadas, conservação, alternativas para produtos substitutos e aos preços e hábitos alimentares (Lopes et al., 2010). As espécies comercializadas industrialmente se diferenciam de acordo com o mercado. As principais espécies comercializadas no mercado local são o tambaqui (Colossoma macropomum, Cuvier, 1818), o curimatá (Prochilodus nigricans, Agassiz, 1829) e o tucunaré (Cichla spp.). No mercado estadual, a demanda tende a ser dominada por peixes de escamas como o tucunaré (Cichla spp.) e o jaraqui (Semaprochilodus theraponura, Fowler, 1906). No mercado nacional, os peixes de couro como a piramutaba (Brachyplatystoma vaillantii, Valenciennes, 1840) e o surubim (Pseudoplattystoma tigrinum, Valenciennes, 1849), assim como os crustáceos lagosta (Panulirus argus, Latreille, 1804) e camarão (Macrobrachium sp.) passam a ser a preferência do consumidor. Nesse mesmo formato, os produtos comercializados também variam de acordo com o mercado de origem. Nos mercados locais, o pescado sofre menor grau de processamento, sendo vendido inteiro ou eviscerado e congelado, enquanto que, para os mercados nacionais e internacionais, o pescado passa por um processo mais elaborado, como vários produtos originados pelo processamento dessas empresas, tais como o fishburguer, a linguiça e o filé de peixe defumado, peixe desossado, patê de peixe, bochecha de garoupa, polpa de pescado, óleo de peixe, grude, bolinho, cubinho e costela (Almeida et al., 2004).

As espécies que possuem o maior valor agregado da atividade da indústria pesqueira ainda são aquelas espécies comerciais que consolidaram nos anos de 1970 e 1980 a atividade da pesca, tais como a piramutaba (Platistomatíctis vaillantii, Valenciennes, 1840), o camarãorosa (Farfantepenaeus subtilis, Pérez-Farfante, 1967), a dourada (Brachyplatystoma flavicans, Castelnau, 1855) e o pargo (Lutjanus purpureus, Poey, 1876), este especialmente comercializado no exterior. Concomitantemente à diminuição da captura dessas espécies comerciais clássicas, tem ocorrido um aumento na produção e na comercialização de espécies antes apreciadas como secundárias. Dentre essas espécies estão o bagre (Bagre sp.), o bandeirado (Bagre bagre, Linnaeus, 1766), a gurijuba (Arius parkeri, Trail, 1832), arraia (Dasiatis spp.) e o cação (Carcharhinus sp) (Almeida et al., 2004).

Segundo Almeida et al. (2004), os motivos expostos em seu estudo para a introdução de novas espécies foram a diminuição dos estoques pesqueiros das espécies tradicionalmente comercializadas, a expansão e diversificação do mercado, o período de defeso de espécies comercializáveis, a agregação de valor ao produto final de espécies de baixo valor comercial e a demanda do mercado por determinadas espécies. A expansão do mercado consumidor pesqueiro ocorreu pelas seguintes razões: crescimento populacional, aumento da importância do pescado comercializado nos supermercados, aumento

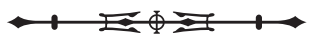


da consciência da alimentação saudável e os processos da preparação industrial.

O mercado consumidor, com a escassez de espécies tradicionalmente comercializadas, teve que se adaptar às novas espécies de pescado, antes não muito apreciadas, a fim de suprir o aumento da demanda populacional ocorrida ao longo dos anos. A partir do momento que a mulher ingressa no universo do mercado econômico pesqueiro, ela passa a refinar sua percepção acerca das espécies apreciadas no mercado consumidor e acerca de quais espécies podem ser inseridas nesse espaço de comercialização. Tal cenário será discutido na seção a seguir, enfatizando esse processo de inserção de novas espécies de pescado por meio do conhecimento feminino.

\section{INTRODUÇÃO DE NOVAS ESPÉCIES DE PESCADO NO MERCADO MUNICIPAL DE CURUÇÁ E NA DIETA DOS PESCADORES DE CARATATEUA}

Mediante o contexto de introdução de novas espécies no mercado nacional, os mercados regionais passaram a sofrer consequências, especialmente a escassez, ao longo dos anos. Nesse sentido, o mercado municipal de Curuçá se ressentiu desse processo, ademais de outras diversas razões relatadas pelos vendedores locais. Indagados, os entrevistados não souberam informar ao certo o período do ingresso de novas espécies para a venda, porém alegam a percepção da escassez de alguns pescados antes vendidos em abundância, tais como a pescada gó (Macrodon ancylddon, Bloch; Schneider, 1801), tainha (Mugil spp.), dourada, piramutaba (Brachyplatystoma vaillantii, Valenciennes, 1840), pescada amarela, serra e mero (Epinephelus itajara, Lichtenstein, 1822)12. Atualmente esses pescados somente são vendidos no período de safra de cada espécie, à exceção do mero, que se encontra em processo de renovação de estoque.

A maioria dos entrevistados, comerciantes do mercado de peixe de Curuçá, já havia sido pescador e atualmente apenas revende o pescado, alegando o abandono da atividade devido às dificuldades encontradas na pesca artesanal. Com a escassez das espécies tradicionais, as viagens se tornaram cada vez mais longas, o que no fim não lhes rendia bons lucros, especialmente em decorrência dos gastos ocorridos durante as viagens. Abaixo, o Quadro 1 mostra as razões que levaram à inserção de novas espécies no mercado de Curuçá, a partir da percepção dos vendedores.

Os entrevistados relataram que a maioria das espécies, atualmente presentes no mercado, antes não eram valorizadas. Quando começaram a vender algumas espécies, por muitas vezes chegavam a doar os produtos por não conseguirem vender, a exemplo da sardinha (Anchovia clupeoides, Swainson, 1839). Atualmente, o consumidor se adaptou às novas espécies, mas considera esses pescados menos importantes e, no linguajar local, 'de segunda',

Quadro 1. Razões para a introdução de novas espécies de pescado no mercado municipal de Curuçá. Fonte: Dados de pesquisa (2012).

\begin{tabular}{|c|c|}
\hline Razões para os vendedores introduzirem novas espécies & $N^{\circ}$ de entrevistados que alegaram as razões identificadas (nove entrevistados) \\
\hline Atendimento da demanda do mercado & 5 \\
\hline Adaptação à oferta de pescado & 6 \\
\hline Sobre-exploração das espécies tradicionais & 9 \\
\hline Crescimento populacional & 9 \\
\hline
\end{tabular}

12 O mero (Epinephelus itajara) é uma das maiores espécies de peixes marinhos, podendo chegar a pesar de $250 \mathrm{~kg}$ a mais de $400 \mathrm{~kg}$ e medir 2,7 metros. Pode ser encontrado em todo o litoral brasileiro; sua pesca, captura, transporte, comercialização, beneficiamento e industrialização foi proibida até setembro de 2007 pela Portaria No 121 de 20 de setembro de 2002 (Brasil, 2002), prevista na Lei de Crimes Ambientais, com uma multa de $\mathrm{R} \$ 700,00$ a $\mathrm{R} \$ 1.000,00$ ou uma pena que variava de um a três anos de detenção a ser aplicada aos infratores que pescassem os meros. Disponível em: < http://www.icmbio.gov.br/cepsul/images/stories/legislacao/ Portaria/2002/p_ibama_121_2002_moratoria5anospescadomero_alterada_P_ibama_42_2007.pdf >. Acesso em: 09 set. 2016.

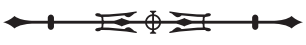


com valores mais baixos, possuindo a preferência pelos pescados mais comercializados considerados 'de primeira'.

Porém, no mercado de Curuçá é difícil encontrar esses pescados avaliados como produto de primeira. Os pescados de maior valor comercial são destinados às indústrias pesqueiras e, na sequência, aos mercados regionais e nacionais, ficando no mercado local as espécies de pouco valor comercial. Os vendedores relatam que vendem os pescados de acordo com o poder aquisitivo da população local. Entre os principais pescados de maior comercialização está a pescada gó, porém sua abundância é influenciada pela sazonalidade da espécie, ocorrendo maior comercialização no período de safra, durante os meses de abril a setembro. Outras espécies que adentraram o consumo local são o cação e a arraia, corroborando o cenário identificado por Freire, Souza e Bentes (2012), para o mercado de Bragança (PA). Neste, a comercialização de tais espécies se assemelha ao mercado de Curuçá. No Quadro 2, a seguir, encontram-se as espécies indicadas pelos vendedores do mercado municipal de Curuçá, sinalizando quais espécies tradicionais são vendidas no local e quais foram inseridas ao longo dos anos.

No período de maior movimentação de turistas na cidade há uma circulação maior no mercado, onde é possível encontrar esses pescados tradicionais, mas ainda assim em pouca quantidade, levando em consideração a localização do município e seu papel de polo pesqueiro na região.

Os pescados vendidos no mercado são geralmente adquiridos junto aos atravessadores, que compram nas comunidades pesqueiras de Curuçá. Caratateua figura como uma das localidades que fornece pescado para esses atravessadores, principalmente no período de safra.

Quadro 2. Produtos tradicionais e novas espécies introduzidas no mercado municipal de Curuçá. Fonte: Dados de pesquisa (2012).

\begin{tabular}{|c|c|}
\hline Pescados tradicionais & $N^{\circ}$ de vendedores que indicaram a espécie (nove entrevistados) \\
\hline Gurijuba & 2 \\
\hline Serra & 2 \\
\hline Pratiqueira & 5 \\
\hline Tainha & 5 \\
\hline Pescada gó & 5 \\
\hline Pescada amarela & 6 \\
\hline Uritinga & 4 \\
\hline Corvina & 3 \\
\hline Bandeirado & 3 \\
\hline Xaréu & 1 \\
\hline Bagre & 1 \\
\hline Anchova & 1 \\
\hline Novas espécies (duas últimas décadas) & $\mathrm{N}^{\circ}$ de vendedores que indicaram a espécie (nove entrevistados) \\
\hline Sardinha & 9 \\
\hline Pacamom & 1 \\
\hline Uricica & 1 \\
\hline Arraia & 6 \\
\hline Cambéua & 3 \\
\hline Cação & 3 \\
\hline Cangatá & 2 \\
\hline
\end{tabular}

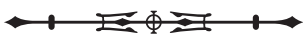


Quando os pescadores chegam das viagens, são as mulheres as responsáveis pela manipulação e acondicionamento do pescado para a comercialização. Separam os peixes que irão consumir e os que serão vendidos. Daí a importância da participação da mulher nesse processo de inserção de novas espécies. A partir de seus conhecimentos tradicionais, sabem quais espécies são aptas ao consumo.

Devido ao quadro de escassez dos recursos pesqueiros, as mulheres, através de seus conhecimentos, passaram a inserir novas espécies, sendo que muitas delas já se encontravam em sua dieta alimentar, porém ainda não havia chegado ao mercado. Quando indagadas como se deu esse processo, relatam que aos poucos foram introduzindo as espécies como uma forma de sobrevivência, pois havia épocas do ano em que não era safra das espécies apreciadas no mercado e que findavam vendendo o que conseguiam pescar a um baixo preço. Dessa forma, é o consumo de espécies variadas no espaço doméstico que fornece a informação necessária para a tentativa de sua inserção no mercado.

As escolhas alimentares são resultantes da interação dos ciclos ecológicos e variações sazonais dos recursos naturais, estruturas habituais do cotidiano, da dinâmica econômica dos mercados locais e regionais e preferências individuais (Murrieta, 2001; Silva, 2007).

A maioria das populações pesqueiras possui particularidades a respeito de suas preferências e aversões alimentares, ou tabus alimentares, referentes à proteína de origem animal. Tais preferências alimentares podem ser explicadas por fatores como a cultura e o ambiente, em função da disponibilidade do recurso, da posição da espécie na cadeia alimentar, e até mesmo de sua importância socialmente dentro da comunidade (Hanazaki, 2001).

O peixe consumido é determinado pelas variações sazonais ecológicas, pela capacidade do pescador ou pela sorte. Duas categorias gerais agregam o peixe à classificação do pescado: o peixe liso ou de pele e o peixe de escama. Ambas são apreciadas por diferentes razões. Os peixes lisos são geralmente apreciados pelo sabor 'forte' e composição fibrosa da carne. E os peixes de escama possuem um sabor mais 'fraco', leve e suave, de fácil digestão (Murrieta, 2001).

A disponibilidade dos recursos pesqueiros na comunidade de Caratateua sofre variações sazonais ao longo do ano. No período de maio a setembro, as pescadoras relatam ser a safra do pescado, quando há uma maior abundância de pescado, permitindo à população garantir uma boa renda e apreciar as espécies disponíveis. Antes desse período, a comunidade se prepara para obter uma boa renda. Os moradores consertam suas redes, motores e canoas, a fim de se 'garantir' para a safra e nela a população quase não consome alimentos industrializados.

Durante a safra, as pescadoras relatam capturar toda espécie de peixe. Percebem que a safra começou quando a sardinha começa a entrar no rio em grande quantidade. Relatam que a sardinha atrai muitas espécies de peixes que se alimentam delas. Nesse período, os pescadores costumam usar a sardinha como isca na pesca de caniço para capturar os peixes maiores, como a pescada amarela. Conseguem, nessa época do ano, pegar os peixes com maior rapidez, num menor período de tempo. Os currais são de grande valia nesse período, por capturar uma grande quantidade de pescado, sem maior esforço por parte dos pescadores.

Fora da época de safra do pescado, os pescadores revezam sua alimentação com os produtos industrializados, como os enlatados, macarrão de preparo instantâneo, e com animais que geralmente criam em seus quintais, como o frango. Segundo Murrieta et al. (2008), com dificuldade de obter os tipos de comida, como o pescado, fora de safra, o frango é o alimento de origem animal de consumo mais frequente, resultante geralmente de criação própria, como estratégia emergencial de sobrevivência.

A carne bovina quase não entra na dieta desses pescadores, alegando não acreditarem que a carne vendida na comunidade seja de boa qualidade e, para compra em outro local, teria que ser na sede municipal, o que seria um gasto maior. Porém, relatam não sentirem falta da carne bovina, pois os alimentos mais apreciados são conseguidos indo pescar na maré, sem precisar gastar nada, a não ser na 
compra da gasolina para o motor de barco. Os moradores que costumam comer carne com mais frequência são os que não vivem da pesca, tais como os comerciantes, professores, funcionários públicos, autônomos etc.

Quando os recursos pesqueiros começaram a entrar em um quadro de escassez, o nicho alimentar teve que se expandir, incluindo na dieta itens menos apreciados, como já mencionado. Pescados que antes não eram consumidos passaram a fazer parte da alimentação, devido às espécies mais apreciadas escassearem ao longo dos anos. Assim, diante da baixa disponibilidade de espécies de importância comercial e muito apreciadas pelos consumidores, pescados tradicionalmente desprezados passaram a fazer parte da dieta alimentar dos pescadores de Caratateua cotidianamente.

A participação feminina teve um papel fundamental nesse processo, visto que são elas, como já mencionado, que trabalham diretamente na manipulação dos pescados capturados. Ou seja, conhecem perfeitamente os recursos naturais capturados (Figura 1), embora muitas vezes não seja reconhecido tal trabalho.

Essa desconsideração das atividades femininas pode ser compreendida a partir dos estudos de gênero, pois nesta perspectiva é possível perceber que aquilo que fora naturalizado como sendo de homem ou de mulher é algo apresentado conforme a cultura na qual o sujeito está inserido. Assim, Laqueur (2001) enfatiza que o sexo é algo inventado e não apenas determinado biologicamente. Consequentemente, as sociedades tendem a silenciar e desconsiderar aquilo que foge ao padrão estabelecido como sendo 'de homem' ou 'de mulher'. As atividades femininas na pesca são exemplares (Figura 2), pois, à revelia de sua importância, ou são consideradas inferiores ou são invisibilizadas. Esse quadro não é diferente em Caratateua.

As múltiplas atividades femininas, algumas delas, juntamente com seus conhecimentos tradicionais, permitem ampliar a percepção na utilização dos recursos naturais, visto que são as mulheres que lidam com as dificuldades diárias de suas famílias, enquanto que seus

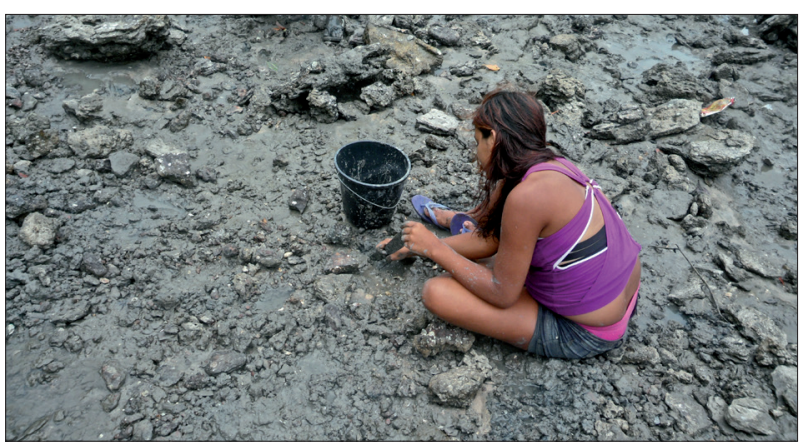

Figura 1. Atividade de extração do molusco sarnambi (Protothaca pectorina, Lamarck, 1818). Foto: Marllen Palheta, 2012.

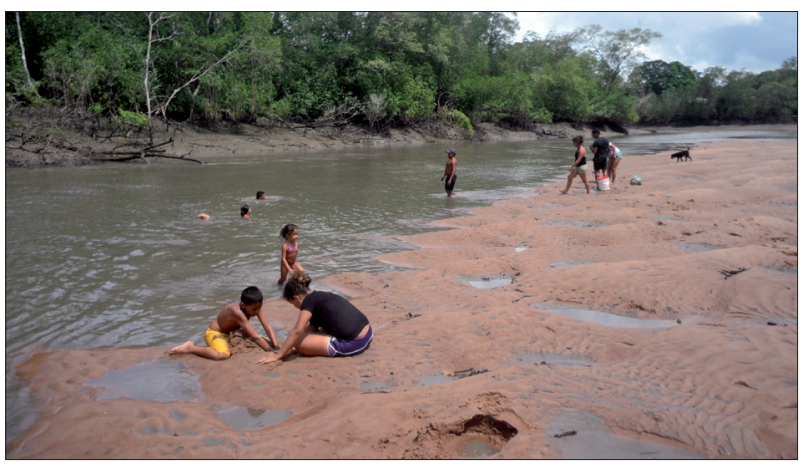

Figura 2. Atividade de mariscagem exercida pelas mulheres da comunidade para o complemento do sustento familiar. Foto: Marllen Palheta, 2012.

maridos estão focados na pesca voltada para o mercado. Sendo assim, são as mulheres que percebem quais espécies podem ser inseridas na alimentação de suas famílias, por apresentarem uma maior sensibilidade na sua percepção. Conforme visto por Ferreira, Jankowsky e Nordi (2009), o processamento e o preparo dos alimentos nas comunidades pesqueiras são realizados por mulheres, cabendo ao homem a responsabilidade da captura.

As mulheres começariam a inserir aos poucos na dieta alimentar de suas famílias as espécies que, antes, não eram apreciadas pelos familiares. Partindo da imposição ditada pelo mercado que consome as espécies de maior valor, tiveram que substituir espécies e reorientar hábitos. É importante notar, no entanto, que as novas espécies não eram desconhecidas, apenas não apareciam como prioridade de consumo.

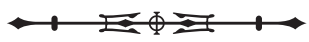


As marisqueiras relatam que, com o passar do tempo, se adaptaram às novas espécies, principalmente no período que o pescado 'falha', como os próprios pescadores denominam. Nesse período, não há como escolher o que alimentar-se do que conseguirem pescar. O relato a seguir é revelador:

Logo quando me casei, meu marido colocava curral, quando dava gó, ele só escolhia as mais graúdas pra vender, as mais miúdas ele trazia pra casa. E pra não estragar, eu lanhava, salgava, ai a gente trocava por farinha. Por isso não tinha necessidade da gente fazer caso desses outros peixes, como a arraia, do cação, do tralhoto, porque tinha outros peixes gostosos e hoje em dia não. (N., 57 anos).

Atualmente os fatores econômicos seguramente influenciam sobre as escolhas alimentares das populações tradicionais. Antes de vender ou doar o pescado capturado, os pescadores reservam suas espécies preferidas, priorizando aquelas que apresentam baixo valor comercial (Silva, 2007).

Segundo Hanazaki e Begossi (2004), a escolha do pescado para o consumo e venda está relacionada a algumas variáveis, tais como a quantidade de espinha, calorias, proteínas, disponibilidade através da pesca, preço e preferências. No caso de Caratateua, as variáveis que mais influenciam na escolha relatada nas entrevistas são a disponibilidade do pescado e preferências pessoais. Há um grande dilema na hora de escolher o peixe de venda e de consumo, pois os pescados que são muito apreciados possuem um preço alto no mercado, como ressalta a fala a seguir:

No verão, o peixe fica escasso, o que vier tem que comer, até por que o que pegamos, já vendemos pro atravessador, aí pra gente aqui fica difícil, nessa época é mais fácil comer peixe em Castanhal, do que aqui, que é beira de mar. (S., 37 anos).

Entretanto, ao contrário do cenário visto na inserção de novas espécies no mercado, na dieta alimentar dos pescadores essa inserção não ocorreu de fato. Durante as entrevistas, quando indagadas sobre inclusão de espécies em sua alimentação, as mulheres relataram que sempre comeram todo tipo de peixe. A diferença repousa no fato de que, antes, podiam optar pelas espécies que mais apreciavam e, atualmente, não possuem essa opção, conforme se observa nos depoimentos abaixo.

Entrevistadora: E quais são os peixes que a senhora vê que estão sumindo?

Pescadora: A gó, espada; no inverno que dá muito peixe, vai começar agora a safra do peixe, no verão quase não dá; agora tá dando, piaba, bagre.

Entrevistadora: E tem algum peixe que antes a senhora não comia e passou a comer devido ao desaparecimento dessas espécies?

Pescadora: Tem, o xaréu, o peixe-pedra, o bagre, a arraia-manteiga. Essa arraia a gente jogava fora, quando vinha uma pescada, cangatá, agora não, tudo que vem a gente come. Olha, quando eu morava com a minha mãe, a gente ia nessa beira, colocava a lamparina perto da água e via os peixes; eles pulavam pra dentro da canoa. Agora não, vamos tarrafear ai na beira e não pega nada mais; de tanta rede que colocam, os peixes nem chegam mais pra cá.

Entrevistadora: E por que a senhora não comia esses peixes que a senhora falou, como a arraia, por exemplo?

Pescadora: A gente comia, só que quando tinha outros a gente preferia os outros; mas, assim, eu gosto de tudo quanto é tipo de peixe.

Entrevistadora: E por que vocês deixavam eles de lado?

Pescadora: Porque tinha outros peixes.

Entrevistadora: Por que eram mais gostosos?

Pescadora: Era, agora não, o que vier a gente come. (F., 47 anos).

O relato evidencia como o mercado passou a conduzir as escolhas para o consumo, ao passo que o conhecimento sobre a variedade de espécies funciona como uma alternativa que amplia o leque de possibilidades para a dieta dessas famílias de pescadores. 
Os peixes de escama ainda estão na preferência da comunidade. $\bigcirc$ Quadro 3 apresenta os peixes inseridos na dieta alimentar dos pescadores de Caratateua e sua relação com o mercado, do ponto de vista da apreciação nesses dois espaços de consumo (mesa do pescador mercado consumidor).

Quadro 3. Espécies de pescado inseridas na dieta alimentar dos pescadores de Caratateua. Legenda: (AB) - Abundante; (A) - Ausência; (O) - Oscilante; (BP) - Baixa presença; (MA) - Muito apreciada; (PA) - Pouco apreciada. Fonte: Dados da pesquisa (2012)

\begin{tabular}{|c|c|c|c|c|}
\hline $\begin{array}{l}\text { Produtos } \\
\text { tradicionais }\end{array}$ & Nome científico & $\begin{array}{l}\text { Presença no } \\
\text { mercado }\end{array}$ & $\begin{array}{c}\text { Presença na } \\
\text { mesa }\end{array}$ & $\begin{array}{c}\text { Apreciado pelos } \\
\text { moradores }\end{array}$ \\
\hline Anchova & Pomatomus saltatrix (Linneaus, 1766) & O & O & MA \\
\hline Bagre & Arius couma (Valenciennes, 1839) & $A B$ & $A B$ & PA \\
\hline Bandeirado & Bagre bagre (Linnaeus, 1766) & O & ○ & MA \\
\hline Corvina & Cynoscion virescens (Cuvier, 1830) & $\bigcirc$ & O & MA \\
\hline Gurijuba & Arius parkeri (Trail, 1832) & $\mathrm{BP}$ & $\mathrm{BP}$ & MA \\
\hline Mero & Epinephelus itajara (Lichtenstein, 1822) & A & A & MA \\
\hline Pescada amarela & Cynoscion acoupa (Lacépêde, 1802) & $\mathrm{BP}$ & $\mathrm{BP}$ & MA \\
\hline Pescada gó & $\begin{array}{l}\text { Macrodon ancylddon } \\
\text { (Bloch; Schneider, 1801) }\end{array}$ & O & O & MA \\
\hline Pratiqueira & Mugil spp. & $\bigcirc$ & O & MA \\
\hline Serra & $\begin{array}{c}\text { Scomberomorus Brasiliensis } \\
\text { (Collette Russo; Zavalla-Camin,1978) }\end{array}$ & $\mathrm{BP}$ & $\mathrm{BP}$ & MA \\
\hline Tainha & Mugil spp. & $\bigcirc$ & $\bigcirc$ & MA \\
\hline Uritinga & Arius proops (Valenciennes, 1839) & $\bigcirc$ & O & MA \\
\hline Xaréu & Caranx spp. & O & O & MA \\
\hline \multicolumn{5}{|c|}{ Novas espécies } \\
\hline Arraia & Dasiatis spp. & $A B$ & $A B$ & PA \\
\hline Bodó & $\begin{array}{l}\text { Hyppostomus cff. verres } \\
\text { (Valenciennes, 1840) }\end{array}$ & $\mathrm{BP}$ & $A B$ & MA \\
\hline Cação & Sphyrna lewini (Grifith; Smith, 1834) & $A B$ & O & PA \\
\hline Cambéua & Arius grandicassis (Valenciennes, 1840) & O & O & PA \\
\hline Cangatá & Arius quadriscutis (Valenciennes, 1840) & O & O & PA \\
\hline Pacamom & $\begin{array}{l}\text { Batrachoides surinamensis } \\
\text { (Bloch; Schneider, 1801) }\end{array}$ & $\mathrm{BP}$ & O & PA \\
\hline Peixe-galo & Selene vomer (Unnaeus, 1758) & $\mathrm{BP}$ & $A B$ & MA \\
\hline Peixe-espada & Trichiurus lepturus ( Lineu, 1758) & $\bigcirc$ & $\mathrm{O}$ & MA \\
\hline Peixe-pedra & Genyatremus luteus (Bloch, 1795) & $\mathrm{BP}$ & $A B$ & MA \\
\hline Piaba & $\begin{array}{c}\text { Brachyplatystoma } \\
\text { Vaillantii(Valenciennes, 1840) }\end{array}$ & $A B$ & $A B$ & MA \\
\hline Sardinha & Anchovia clupeoides (Swainson, 1839) & $A B$ & $A B$ & PA \\
\hline Tralhoto & Anableps anableps (linnaeus, 1759) & A & $A B$ & PA \\
\hline Uricica & Cathorops spixii (Agassiz, 1829) & $\bigcirc$ & 0 & MA \\
\hline
\end{tabular}


Fora da época de safra, a população tem que se alimentar com o que está disponível. Nesse período, os pescadores informaram que, devido à grande abundância de tralhoto, piaba, bagres etc., essas espécies passam a ser os pescados consumidos fora de safra. Para a piaba ${ }^{13}$, há um caso interessante a relatar. No mês de julho, em uma praia próxima da comunidade é realizado um festival de piaba, quando os pescadores contam que essa é uma espécie que dá o ano inteiro na região, principalmente no período de safra. Entretanto, o tralhoto, apesar de estar inserido na dieta dos pescadores, ainda encontra-se ausente do mercado consumidor.

Os demais pescados de pele mencionados, como uritinga, cangatá, cambéua e bandeirado, encontram-se oscilantes tanto no mercado quanto na mesa dos pescadores, estando disponíveis apenas em determinadas épocas do ano. Porém, é possível se observar que o bandeirado e a uritinga, apesar de serem oscilantes, são muito apreciados nos dois setores mencionados, ao contrário de espécies como o cangatá e a cambéua, que, apesar de terem sido inseridas na dieta do pescador e no mercado, ainda são pouco apreciadas. De toda forma, a comparação do Quadro 1 com os Quadros 3 e 4 sugere uma relação direta entre o consumo alimentar dos pescadores e a inserção de novas espécies no mercado.

Os peixes de pele, apesar de estarem inseridos na dieta dos pescadores de Caratateua, são pouco apreciados, conforme visto no Quadro 3, por serem considerados reimosos ${ }^{14}$. Sobre a arraia, os pescadores alegaram ter certo receio de comerem, por ter ferrão, e relatam ter medo de encontrar ferrão na carne, principalmente quando alimentam seus filhos. Porém, apesar de não serem muito apreciadas, bagres e arraias têm presença constante no mercado e na alimentação dos pescadores.

Barthem e Goulding (1997), durante seus estudos na Amazônia, verificaram que há uma abundância de estoques de arraias, suficientes para serem exploradas comercialmente. Porém, na Amazônia, o hábito de consumir arraias ainda é muito restrito, sendo considerado um pescado de baixo valor comercial.

Conforme visto também por Castro (2005) na região do Tapajós, os pescados mais apreciados pelos pescadores locais são os peixes de escamas, como as pescadas em geral. Em Caratateua observa-se a mesma preferência; todavia, as mais apreciadas encontram-se oscilantes no mercado e na dieta da comunidade, como a pescada gó, a pratiqueira, a tainha e a anchova,por se encontrarem em nível de sobrepesca. A incidência dessas espécies na região é principalmente no período de safra, falhando nas demais épocas do ano.

A comunidade de Caratateua enfatizou a necessidade de práticas de manejo para minimizar a sobre-exploração do recurso. Uma prática muito mencionada foi a implantação do defeso de espécies comerciais exploradas, a fim de renovar os estoques pesqueiros. Relataram que, se houvesse defeso na região, pescarias no período reprodutivo iriam diminuir. Outro fator abordado refere-se à questão de a fiscalização ser precária, pois, apesar de ser uma reserva extrativista, muitos pescadores de fora do estado pescam na região, prejudicando a pesca artesanal local. A fala de uma entrevista figura de forma recorrente nas conversas com todos os moradores da comunidade e é reveladora: "se continuarmos pescando muito sem repor, um dia vai acabar o peixe, os mariscos, tudo que vem do mar".

13 Observando as espécies consumidas, foi possível averiguar que o pescado denominado como piaba pelos moradores de Caratateua, corresponde a um tipo pequeno de piramutaba.

${ }^{14}$ A reima é uma classificação atribuída a proibições e restrições no consumo de determinados alimentos. Está dividida em alimentos perigosos (reimosos) e não perigosos (não reimosos) à saúde física do consumidor (Murrieta, 2001). Porém, o presente trabalho não possui objetivo de aprofundar na questão da reima, mas esclarecer seu significado.

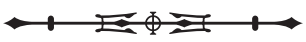


É necessária, no próprio olhar dos moradores, portanto, a adoção de medidas emergenciais para garantir os estoques pesqueiros futuros. Caso isso não ocorra, poderá se concretizar a fala mencionada por quase todas as mulheres entrevistadas.

\section{CONSIDERAÇÕES FINAIS}

O município de Curuçá é um local privilegiado pela sua localização, por se encontrar às margens de um estuário rico em recursos naturais. $\bigcirc$ distrito de Caratateua, encontrado dentro da Resex Mãe Grande de Curuçá, está inserido no contexto de populações tradicionais, pois estas dependem das atividades de pesca e agricultura. Apesar da distância da sede municipal, a comunidade apresenta grande importância por abastecer o mercado local com pescados. Sendo assim, neste artigo buscouse problematizar e questionar em que medida 0 conhecimento tradicional da mulher contribui para a inserção e comercialização no mercado de novas espécies de pescado e em que medida esse conhecimento garante novas espécies na mesa das famílias de pescadores.

A partir do levantamento socioeconômico, foi possível estabelecer uma aproximação descritiva acerca da comunidade de Caratateua, evidenciando a participação feminina na atividade pesqueira da localidade. Observou-se que a comunidade é marcada por uma divisão de trabalho pautada em uma lógica de gênero, ou seja, as mulheres são responsáveis por cuidar da casa, pescar na beira do rio e no mangue e trabalhar na roça, enquanto que seus maridos pescam em alto mar. As artes de pesca mais utilizadas pela comunidade são os currais e o puçá na pesca do camarão.

Foi constatado que o mercado em geral teve que se adaptar a uma nova realidade para o consumo de pescado, pois a escassez das espécies apreciadas vem se impondo. Tal movimento se expandiu também para o setor industrial, influenciando as comunidades pesqueiras que fornecem pescados para essas empresas.

Como apresentado, a participação feminina mostrou-se de importância fundamental na inserção de novas espécies no mercado local, visto que são as mulheres que lidam diariamente com os pescados capturados, conhecendo perfeitamente suas características através dos conhecimentos tradicionais repassados pelas gerações passadas. As principais espécies inseridas no mercado de Curuçá foram a sardinha, o pacamom, a uricica, a arraia, a cambéua, o cação e o cangatá, antes ausentes nesse espaço de comercialização, mas presentes na mesa dos moradores de Caratateua, ainda que pouco apreciadas.

Assim como na inserção referente ao mercado, a participação da mulher se destaca também na comunidade, mas é importante observar que as espécies relatadas como novas na dieta sempre estiveram presentes, apenas não eram apreciadas ou priorizadas para o consumo. Assim, a comunidade sempre teve contato com essas espécies, tais como o peixe-pedra, a arraia, o cação, a sardinha etc., porém não as consumiam por dispor de outras opões em forma abundante, como a gurijuba, a tainha, a pescada amarela etc. $\bigcirc$ resultado da pesquisa mostrou que a substituição de pescados mais apreciados pelos menos apreciados na mesa dos moradores se deu pela necessidade de contemplar a demanda do mercado e comercialização de espécies de maior valor. Assim, permaneceram na mesa do pescador as espécies consideradas de baixo valor comercial, ainda que menos apreciadas, como os bagres, ou até mesmo as espécies que ainda nem chegaram ao mercado, como é o caso do tralhoto.

No período fora de safra do pescado, é possível visualizar de forma clara o cenário relatado nas entrevistas: pescadores que têm que se contentar com o que conseguem pescar, quadro totalmente oposto ao de algumas décadas atrás. Os produtos industrializados começaram a fazer parte da dieta dos pescadores e o consumo de frango aumenta significativamente, substituindo o peixe. Porém, a carne bovina não é muito apreciada pela comunidade, já que os moradores não confiam na sua qualidade. 
Sendo assim, é a pesca das mulheres que garante uma boa parte do sustento das famílias, não somente no período fora de safra do pescado, como ao longo de todo ano. Por apresentarem uma variedade de atividades em busca do sustento familiar, quando não o peixe, recorrem ao mangue em busca dos mariscos e trabalham na roça, cultivando mandioca, fabricando os produtos derivados da mesma, tão apreciados na comunidade, a exemplo da farinha.

Tais observações e constatações evidenciam que, de fato, o trabalho das mulheres na pesca é de relevância não apenas no processo de captura, mas também na dinâmica do mercado. As inovações relacionadas à inserção de espécies de peixes no consumo local são exemplares e revelam relações sociais de gênero nas quais as mulheres superam aspectos binários e onde não lhes caberiam exercer determinadas atividades produtivas. Em que pesem as naturalizações do ser masculino e feminino no setor pesqueiro, as mulheres contribuem de maneira decisiva nas inovações e tecnologias sociais desta atividade.

Mesmo com todos os entraves no setor pesqueiro, as pescadoras de Caratateua alegam gostar da profissão e dizem que atualmente não deixariam de exercê-la, independente de conseguir outra atividade, por ser um trabalho que aprenderam desde criança e, de muitas, é a única profissão que sabem exercer, além da agricultura. Esse conhecimento tradicional é de fundamental importância no setor pesqueiro e, como visto, contribui para que haja novas possibilidades de uso dos recursos naturais, embora, perante a sociedade, a atividade pesqueira exercida pelas mulheres não seja reconhecida como deveria ser, pois muitas vezes são consideradas apenas ajudante de seus maridos.

Este artigo evidencia, por fim, o pensamento conservacionista como forte alternativa para minimizar os problemas ambientais relacionados aos impactos ocorridos no setor pesqueiro com a sobre-exploração das espécies. Medidas de manejo dos recursos pesqueiros deveriam ser implantadas, como o defeso para as espécies de pescado mais exploradas, a fim de renovar os estoques pesqueiros e ao mesmo tempo consolidar uma maior fiscalização por parte dos órgãos públicos competentes. Tal como na inserção de novas espécies de pescado na mesa das famílias de pescadores e no mercado, a mulher marisqueira pode ser a protagonista dessa nova possibilidade.

\section{AGRADECIMENTOS}

Às pescadoras de Caratateua e aos vendedores do mercado municipal de Curuçá, pelas informações e acolhimento; ao Instituto Chico Mendes de Conservação da Biodiversidade (ICMBIO), pela concessão da licença 33232-1. À Coordenação de Aperfeiçoamento de Pessoal de Nível Superior (CAPES), que, através do Programa de Pós-Graduação em Ecologia Aquática e Pesca (PPGEAP/ UFPA), viabilizou a pesquisa de mestrado de Marllen Karine da Silva Palheta, originando este artigo.

\section{REFERÊNCIAS}

ALENCAR, Edna Ferreira. Gênero e trabalho nas sociedades pesqueiras. In: FURTADO, Lourdes Gonçalves; LEITÃO, Wilma Marques; DE MELLO, Alex Fiuza (Org.). Povos das águas: realidade e perspectiva na Amazônia. Belém: MPEG, 1993. p. 63-81.

ALMEIDA, Marineide Pereira. Trabalhos femininos e papéis sociais em uma comunidade rural no nordeste paraense. Projeto Integrado: Produção familiar rural paraense. In: HÉBETTE, J. (Org.). No mar, nos rios e na fronteira: faces do campesinato no Pará. Belém: UFPA, 2002. p. 85-110. v. 1.

ALMEIDA, Oriana Trindade de; CABRAL, Wilson; ANDROCZEVECZ, Scheyla; AMARAL, Lucilene; ARAÚJO, Bárbara. Caracterização da indústria pesqueira na Amazônia. In: PETRERE, Miguel (Org.). O setor pesqueiro na Amazônia: análise da situação atual e tendências do desenvolvimento da indústria da pesca. Manaus: ProVárzea/IBAMA, 2004. p. 61-75.

ALMEIDA, José Bruno Araújo de. Efeito de características ambientais no uso dos canais-de-maré por três espécies de peixes bentófagos durante o período transição-seca no estuário de Curuçá (Pará-Brasil). 2009. 93 f. Dissertação (Mestrado em Ecologia Aquática e Pesca) - Universidade Federal do Pará, Belém, 2009.

ARRUDA, Rinaldo Sérgio Vieira. Populações tradicionais e a proteção de recursos naturais em unidades de conservação. Revista Ambiente e Sociedade, Campinas, NEPAN/UNICAMP, v. 2, n. 5, p. 79-93, 2000. 
BATISTA, lane Maria da Silva. Participação, organização social e desenvolvimento sustentável no contexto da Resex Mãe Grande de Curuçá. 2010. 199 f. Dissertação (Mestrado em Planejamento do Desenvolvimento) - Universidade Federal do Pará, Núcleo de Altos Estudos Amazônicos - NAEA, Belém, 2010.

BARTHEM, Ronaldo; GOULDING, Michael. Os bagres balizadores: ecologia, migração e conservação de peixes amazônicos. Tefé: Sociedade Civil Mamirauá; Brasília, DF: CNPq, 1997.

BRASIL. Lei 9.985, de 18 de Julho de 2000. Regulamenta o art. 225, $\S 1$ १o, incisos I, II, III e VII da Constituição Federal, institui o Sistema Nacional de Unidades de Conservação da Natureza e dá outras providências. Diário Oficial [da] República Federativa do Brasil, Brasília, DF, 18 jul. 2000. Seção 1, p. 41.

BRASIL. Portaria n 121, 20 de Setembro de 2002. Diário Oficial [da] República Federativa do Brasil, Brasília, DF, 23 set. 2002. Seção 1, p. 59.

BEAUVOIR, Simone de. Segundo sexo: fatos e mitos. Rio de Janeiro: Nova Fronteira, 1980.

BENTES, Bianca. Diagnóstico da pesca no litoral paraense. 2004. 154 f. Dissertação (Mestrado em Zoologia) - Universidade Federal do Pará, Museu Paraense Emilio Goeldi, Belém, 2004.

CARDOSO, Denise. Catadoras de caranguejo e saberes tradicionais na conservação de manguezais da Amazônia brasileira. Revista Estudos Feministas, Santa Catarina, v. 15, p. 485-490, 2007.

CASTRO, Mauro André Costa de. Alimentação e reima no vale do Tapajós. 2005. 71 f. Trabalho de Conclusão de Curso (Graduação em Ciências Sociais) - Universidade Federal do Pará, Belém, 2005.

CHAVES, Aloma Tereza Pinho de Vasconcelos. Gestão pública e participação: uma análise do Conselho Deliberativo da Reserva Extrativista Mãe Grande de Curuçá. 2010. 177 f. Dissertação (Mestrado em Gestão de Recursos Naturais e Desenvolvimento Local na Amazônia) - Universidade Federal do Pará, Núcleo de Meio Ambiente - NUMA, Belém, 2010.

COELHO, Geisa Costa. Da Escola ao embarque: mulheres na marinha mercante do Brasil. 2013. 137 f. Dissertação (Mestrado em Ciências Sociais) - Universidade Federal do Pará, Belém, 2013.

CUNHA, Manuela Carneiro. Populações tradicionais e a Convenção da Diversidade Biológica. Estudos Avançados, São Paulo, v. 13, n. 36, p. 147-163, 1999.

DIEGUES, Antônio Carlos; ARRUDA, Rinaldo Sérgio Vieira (Org.) Saberes tradicionais e biodiversidade no Brasil. 4. ed. Brasília: Ministério do Meio Ambiente, 2001. 176 p. v. 4.

FERREIRA, Marina Vianna; JANKOWSKY, Mayra; NORDI, Nivaldo. História e mudanças do sistema alimentar de pescadores: uma comunidade no litoral de São Paulo, Brasil. Interciência, Caracas, v. 34, n. 10, p. 696-702, out. 2009.
FIGUEIREDO, Elida Moura; SANTANA, Graça. Mulheres do Sal: o cotidiano feminino nas comunidades da ilha de Algodoal/ Maiandeua, Maracanã-PA. In: ÁLVARES, Maria Luzia Miranda; SANTOS, Eunice Ferreira dos; CANCELA, Cristina Donza (Org.). Mulheres e gênero: as faces da diversidade. Belém: GEPEM, 2009. p. 213-228. v. 1.

FIGUEIREDO, Elida Moura. Uma estrada na reserva: impactos socioambientais da PA-163 em Mãe Grande, Curuçá (PA). 2007. 132 f. Dissertação (Mestrado em Ciências Ambientais) - Universidade Federal do Pará, Belém, 2007.

FREITAS, Henrique; OLIVEIRA, Mírian; SACCOL, Amarolinda Zanela; MOSCAROLA, Jean. O método de pesquisa Survey. Revista de Administração, São Paulo, v. 35, n. 3, p. 105-112, jul.-set. 2000.

FREIRE, Julliany Lemos; SOUZA, Adelson Silva de; BENTES, Bianca. Aspectos econômicos e higiênico-sanitários da comercialização do pescado no município de Bragança (PA). Biota Amazônia REBIA, v. 1, p. 17-28, 2012.

HANAZAKI, Natalia. Ecologia de caiçaras: usos de recursos e dieta. 2001. 213 f. Tese (Doutorado em Ecologia) - Universidade de Campinas, Instituto de Biologia, Campinas, 2001.

HANAZAKI, Natalia; BEGOSSI, Alpina. Dieta de populações de pescadores. In: BEGOSSI, Alpina (Org.). Ecologia de pescadores da Mata Atlântica e da Amazônia. São Paulo: Hucitec, 2004. p. 149-166.

HERCOS, Alexandre Pucci. Diversidade e variabilidade espaçotemporal da ictiofauna da região estuarina do rio Curuçá, município de Curuçá, Pará, Brasil. 2006. 123 f. Dissertação (Mestrado em Zoologia) - Universidade Federal do Pará, Museu Paraense Emílio Goeldi, Belém, 2006.

ISAAC-NAHUM, Victoria Judith; BATISTA, Vandick da Silva; VIANA, João Paulo. Exploração e manejo dos recursos pesqueiros da Amazônia. In: RUFFINO, Mauro Luis (Org.). A pesca e os recursos pesqueiros na Amazônia. Manaus: EDUA, 2004. p. 57-135. v. 1.

ISAAC-NAHUM, Victoria Judith. Explotação e manejo dos recursos pesqueiros do litoral amazônico: um desafio para o futuro. Ciência Cultura, v. 58, n. 3, p. 33-36, 2006.

ISAAC-NAHUM, Victoria Judith; BARTHEM, Ronaldo B. Os recursos pesqueiros da Amazônia brasileira. Boletim do Museu Paraense Emilio Goeldi. Série Antropologia, Belém, v. 11, n. 2, p. 295-339, 1995.

ISAAC-NAHUM, Victoria Judith; RUFFINO, Mauro L. Estatística pesqueira no baixo Amazonas: experiência do Projeto Iara. Brasília: IBAMA, 2000. p. 201-224. (Coleção Meio Ambiente. Série Estudos Pesca, v. 22).

LAQUEUR, Thomas Walter. Inventando o sexo: corpo e gênero dos gregos a Freud. Rio de Janeiro: Relume Dumará, 2001.

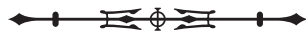


LOPES, Maria Lúcia Bahia; COSTA, Patrício Alves; SANTOS, Jesus do Socorro Barroso dos; CUNHA, Sávio de Jesus Tourinho da; SANTOS, Marcos Antônio Souza dos; SANTANA, Antônio Cordeiro de. Mercado e dinâmica espacial da cadeia produtiva da pesca e aquicultura na Amazônia. Belém: Banco da Amazônia S. A., 2010. 50 p. v. 1. (Estudos Setoriais 7).

MALINOWSKI, Bronislaw. Argonautas do pacifico ocidental: um relato do empreendimento e da aventura dos nativos nos arquipélagos da Nova Guiné Melanésia. São Paulo: Abril Cultural, 1976. (Pensadores, 43).

MANESCHY, Maria Cristina. Da casa ao mar: papéis das mulheres na construção da pesca responsável. Proposta, Rio de Janeiro, p. 82-91, 2000.

MANESCHY, Maria Cristina. A mulher está se afastando da pesca? Continuidade e mudança no papel da mulher na manutenção doméstica entre famílias de pescadores no litoral do Pará. Boletim do Museu Paraense Emilio Goeldi. Série Antropologia, Belém, v. 11, n. 2, p. 145-166, 1995.

MARTINS, Almira Alice Fonseca Araújo. Caminho das águas: proposta para o aproveitamento de um subproduto ictiológico na Reserva Extrativista Mãe Grande de Curuçá, Pará, Brasil. 2010. 213 f. Dissertação (Mestrado em Gestão de Recursos Naturais e Desenvolvimento Local da Amazônia) - Universidade Federal do Pará, Núcleo de Meio Ambiente - NUMA, Belém, 2010.

MCGRATH, David Gibbs; CASTRO, Fábio de; CÂMARA, Evandro; FUTEMMA, Célia. Manejo comunitário de lagos de várzea e o desenvolvimento sustentável da pesca na Amazônia. Papers do NAEA, Belém, v. 58, n.1, p. 1-26, 1996.

MCGRATH, David Gibbs; CALABRIA, Juliana; AMARAL, Benedito do; FUTEMMA, Célia; CASTRO, Fábio de. Varzeiros, geleiros e o manejo dos recursos naturais na várzea do Baixo Amazonas. Papers do NAEA, Belém n. 4, p. 1-25, 1991.

MEAD, Margareth. Macho e Fêmea. Petrópolis: Vozes, 1971.

MORAIS, Gisele Cavalcante. Estrutura das assembléias de macroinvertebrados de substratos rochosos no litoral de Curuçá, Nordeste do Pará, Brasil. 2011. 92 f. Dissertação (Mestrado em Ecologia Aquática e Pesca) - Universidade Federal do Pará, Belém, 2011.

MOTTA-MAUÉS, Maria Angélica. Trabalhadeiras e camarados: relações de gênero, simbolismo e ritualização numa comunidade amazônica. Belém: EdUFPA, 1993.

MURRIETA, Rui Sérgio Sereni. Dialética do sabor: alimentação, ecologia e vida cotidiana em comunidades ribeirinhas da Ilha de Ituqui, Baixo Amazonas, Pará. Revista de Antropologia, São Paulo, USP, v. 44, n. 2, 2001.
MURRIETA, Rui Sérgio Sereni; BAKRI, Maissa Salah; ADAMS, Cristina; OLIVEIRA, Perpétuo Socorro de Souza; STRUMPF, Roberto. Consumo Alimentar e Ecologia de Populações Ribeirinhas em Ecossistemas Amazônicos: um estudo comparativo. Revista de Nutrição, v. 21, p. 123-134, 2008.

OLIVEIRA, Diogo Marques; FREDOU, Thierry; LUCENA, Flávia. A pesca no Estuário Amazônico: uma análise uni e multivariada. Boletim do Museu Paraense Emílio Goeldi. Ciências Naturais, Belém, v. 2, n. 2, p. 11-21, maio-ago. 2007.

PALHETA, Glauber David Almeida. Composição e distribuição espaço temporal de ovos e larvas de peixes, nos estuários dos rios Curuçá e Muriá (Curuçá-Pará). 2005. 88 f. Dissertação (Mestrado em Ciência Animal) - Universidade Federal do Pará, Belém, 2005.

PATEMAN, Carole. Críticas feministas a la dicotomía público/ privado. In: CASTELLS, Carme (Org.). Perspectivas feministas en teoría política. Barcelona: Paidós, 1996.

PINHEIRO, Ludmila Assunção; FRÉDOU, Flávia Lucena. Caracterização geral da pesca industrial desembarcada no estado do Pará. Revista Científica da UFPA, Belém, v. 4, 2004. 16 p.

QUEIROZ, Jacirene da Silva. Ecoturismo de base comunitária na Amazônia oriental: o caso do Instituto Tapiaim em Curuçá-PA. 2011. 147 f. Dissertação (Mestrado em Agriculturas Familiares e Desenvolvimento Sustentável) - Universidade Federal do Pará, Belém, 2011.

SANTOS, Geraldo Mendes; SANTOS, Ana Carolina Mendes. Sustentabilidade da pesca na Amazônia. Estudos Avançados, São Paulo, v. 19, n. 54, 2005.

SANTOS, Laura do Socorro da Rocha. O Arranjo Produtivo Local da Pesca no estado do Pará: identificação e mapeamento dos municípios especializados - 1998 a 2003. 2005. 130 f. Dissertação (Mestrado em Economia) - Universidade da Amazônia, Belém, 2005.

SILVA, Andréa Leme da. Comida de gente: preferências e tabus alimentares entre os ribeirinhos do Médio Rio Negro (Amazonas, Brasil). Revista de Antropologia, São Paulo, USP, v. 50, n. 1, 2007.

SILVA, Raimundo Reinaldo Carvalho da. Gerenciamento Costeiro Integrado: Proposta de Inserção de Concepções Subsidiárias ao Plano Diretor Municipal de Curuçá - Pará. 2011. 118 f. Dissertação (Mestrado em Gestão de Recursos Naturais e Desenvolvimento Local na Amazônia) - Universidade Federal do Pará, Núcleo de Meio Ambiente - NUMA, Belém, 2011.

SIMONIAN, Ligia Terezinha Lopes. Mulheres, gênero e desenvolvimento na Amazônia brasileira: resistências, contradições e avanços. In: SIMONIAN, Ligia Terezinha Lopes. Mulheres da floresta amazônica: entre o trabalho e a cultura. Belém: UFPA/ NAEA, 2001. p. 33-62. 
SOUSA, Ranieri Garcez Costa; FREITAS, Carlos Edwar de Carvalho; WITKOSK, Antônio Carlos; BRITO, Marco Antônio Souza. Mudanças sociais na pesca artesanal: um estudo a partir da pressão sobre o estoque de tambaqui (Colossoma macropomum, Cuvier, 1818) do Lago Grande de Manacapuru (AM). In: ENCONTRO DA ASSOCIAÇÃ̃O NACIONAL DE PESQUISA E PÓS-GRADUAÇÃO EM AMBIENTE E SOCIEDADE, 4., 2008, Brasília. "Mudanças Ambientais Globais" A contribuição da ANPPAS ao debate. Anais... Brasília: ANPPAS, 2008. p. 1-13.
TORRES, Vera Lúcia Scaramuzzini. Envelhecimento e pesca: redes sociais no estuário amazônico. Belém: NAEA, 2004. v. 1.

WOORTMANN, Ellen Fensterseifer. Da Complementaridade à Dependência: a mulher e o ambiente em comunidades pesqueiras do Nordeste. Série Antropologia, Brasília, v. 111, p. 1-115, 1991. 